v. 01, n. 01 : pp.49-56, 2005 ISSN $1808-0448$
Revista Gestão Industrial

\title{
ESTUDO DE CASO EM UMA EMPRESA NORTE-AMERICANA: IMPLEMENTAÇÃO DA GESTÃO DO CONHECIMENTO NA COMERCIALIZAÇÃO INTERNACIONAL DE MADEIRA
}

\author{
CASE STUDY IN A NORTH AMERICAN COMPANY: \\ IMPLEMENTATION OF KNOWLEDGE MANAGEMENT IN THE \\ INTERNATIONAL COMMERCIALIZATION OF LUMBER \\ Thompson Copperfield Ribas von Agner ${ }^{1}$; Carlos Cezar Stadler ${ }^{2}$ \\ ${ }^{1}$ CEFET-PR/Unidade de Ponta Grossa, CESCAGE, tvonagner@brtrubo.com \\ ${ }^{2}$ CEFET-PR/Unidade de Ponta Grossa, cstadler@pg.cefetpr.br
}

Recebido para publicação em: 20/12/2004

Aceito para a publicação em: 13/03/2005

\begin{abstract}
RESUMO
Este artigo visa demonstrar a necessidade de implementação da Gestão do Conhecimento em empresas de pequeno porte norte americanas que comercializam madeira de pinus. Esta necessidade pôde ser observada diante da dificuldade encontrada pelos novos funcionários na realização e aprendizado de suas atividades, pois os mesmos não possuíam como suporte material que explicitasse os processos. Os objetivos foram de levantar os fatores que dificultavam a implementação e diagnosticar as barreiras para assim, elaborar métodos que as superassem. A metodologia utilizada foi a de estudo de caso, que serviu para escalonar as várias etapas dos processos que envolvem a comercialização da madeira de pinus brasileira no mercado norte americano e propor métodos necessários para a utilização da Gestão do Conhecimento na organização.
\end{abstract}

Palavras chave: Gestão do Conhecimento - Comercialização Internacional, Indústria Madeireira.

\section{Introdução}

A implementação de um Sistema de Gestão do Conhecimento em empresas de comercialização internacional de madeira de pinus seria de grande benefício para as mesmas devido à carência de material explicito desta atividade.

Com os mercados cada vez mais exigentes as organizações necessitam estar em constante processo de inovação, tanto tecnológica, quanto de desenvolvimento e aprimoramento de modelos de gestão.

Davenport e Prusak (1998) afirmam que as organizações de maior sucesso são aquelas onde a gestão do conhecimento faz parte das atividades de todos os membros. Thurow (1997) explana que as empresas mais inovadoras são as que derrubam as barreiras funcionais e criam uma 
teia entre invenção, projeto, fabricação, vendas, logística e serviços, permitindo que as decisões sejam tomadas nos níveis inferiores da organização. Choo (1995) afirma que as empresas que permanecem ativas no mercado globalizado têm o conhecimento como sendo um dos seus principais recursos estratégicos. Já Leonard (1998) demonstra que empresas com maior capacidade de inovação são aquelas que demonstram uma maior capacidade para gerar e gerir conhecimentos.

Este estudo de caso foi realizado em uma organização norte americana de pequeno porte, com sede na cidade de Seattle, que comercializa madeira reflorestada. Em sua fase inicial de constituição foi concebida como uma empresa familiar, algo que é característico neste ramo de organização nos Estados Unidos. O objetivo inicial dos membros da organização era a comercialização de madeira somente dentro do mercado interno norte americano e o volume de comercialização era suficiente para os membros envolvidos, não havendo a necessidade de se contratar um maior número de profissionais. Os familiares realizavam todos os procedimentos necessários para que a organização prosperasse naquela conjuntura de mercado.

Com o passar dos anos, a organização observou dois marcantes fatores que a motivou a passar do patamar de uma organização familiar, que comercializava somente dentro do território norte americano, para um nível de maior estrutura, onde pudesse abranger as novas necessidades do mercado e permanecer comercialmente ativa. O primeiro fator observado, pelas organizações, foi um crescente aumento no consumo de produtos de madeira para acabamento residencial, tais como portas, rodapés e molduras de acabamento, componentes de janelas, entre outros, isto motivado pelo crescimento do mercado de construção civil, o segundo fator foi a intensificação na proteção dos recursos florestais naturais norte americanos que estavam se tornando escassos devido a falta de planejamento e controle por parte do governo. Diante desses fatores a organização percebeu a necessidade de adquirir madeira fora do território norte americano.

Optou-se por adquirir madeira em paises como a Nova Zelândia, Chile, Argentina, Rússia, Brasil entre outros grandes produtores mundiais. Conseqüente, houve a necessidade de ampliar o quadro de profissionais capazes de realizar estas novas tarefas e, assim, ocorreu a entrada de novos membros para a organização. Diante dessa necessidade, o estudo observou que existiam dificuldades no processo de treinamento, pois a organização não possuía material de suporte que explicitasse os processos.

Com o passar do tempo, estes fatores foram observados pelas demais empresas do ramo madeireiro, gerando assim a necessidade de ampliar os processos de conhecimento dos trâmites de negociação internacional que ainda não eram plenamente compreendidos e que ainda ao final do processo de levantamento de dados, permaneciam na esfera tácita.

O estudo teve como objetivo levantar os fatores que dificultavam a implementação do processo de aprendizagem dos novos integrantes da equipe e diagnosticar as barreiras que 
impediam a realização do processo, assim pode-se elaborar métodos que superassem tais dificuldades e demonstrar a necessidade da utilização da Gestão do Conhecimento.

No levantamento das características da organização estudada observou-se que os membros possuíam em média, 21 anos de experiência no ramo madeireiro, e que eram detentores de um profundo conhecimento a respeito dos processos que constituem o ramo, tais como: mercado, transportes, logístico e qualidade, entre outros. Foi observado também, que este conhecimento em sua quase totalidade, foi adquirido através de processos tácitos e que pouco foi adquirido por meios explícitos. Sendo o processo tácito de aquisição de conhecimento muito comum entre as organizações de pequeno e médio porte que realizam esta atividade. Esta forma de aquisição de conhecimento é uma das principais e mais marcantes barreiras para a criação de um sistema de gestão do conhecimento. Nonaka e Takeuchi (1997) explanam o conhecimento como sendo em grande parte tácito, isto é algo altamente individual, algo intrínseco aos valores, experiências e ideais dos indivíduos.

A organização estudada possui 25 anos de atuação no mercado e conta atualmente com uma equipe de oito pessoas formada por vendedores, compradores e pessoal de apoio, sendo que, alguns compradores, se localizam no Brasil e outros na Rússia. A principal atuação da organização é a comercialização de informações referentes à madeira de pinus semi-beneficiada, sendo, em sua grande maioria, originada em reflorestamentos brasileiros e russos e uma pequena quantidade oriunda do Alaska. Devido às tecnologias em comunicação a equipe de compra possui flexibilidade para estar em áreas remotas efetuando transações comerciais e, ainda, poder estabelecer contato imediato com a sede em Seattle, proporcionando o cruzamento de informações e produzindo conhecimento. Esta facilidade mantém a equipe sempre atualizada, o que gera maior eficiência e possibilita maiores vantagens nas transações.

\section{Levantamento de informações}

Com o estudo realizado na organização, levantou-se que um dos principais fatores para o não compartilhamento, de forma explicita, do conhecimento é o temor que outras organizações possam vir a conhecer os processos individuais que cada organização possui, e assim, perderem suas vantagens competitivas. Foi também observado que a empresa não está próxima de se tornar uma organização do conhecimento, pois trabalha basicamente na transformação de dados fornecidos por indicadores de mercado e por clientes, e os converte em informações que são comercializadas a clientes e, inclusive, competidores. Constatou-se que a forma mais utilizada de conversão do conhecimento é o da socialização, isto ocorre devido ao fato de haver pouco material explícito sobre as formas muito peculiares do mercado de comercialização internacional de pinus. Quase todo 
conhecimento é passado de forma tácita por meio da imitação, prática ou de compartilhamento de experiências.

Foi também observado um outro fator que dificultava a implantação de um Sistema de Gestão do Conhecimento na organização estudada, a resistência a mudanças. Constatou-se também, através de relatos, que o mesmo ocorria em outras empresas do mesmo ramo. Na grande maioria das empresas levantou-se que os profissionais já trabalhavam nestas funções há muito tempo, o que dificultava a mudança nos padrões quanto ao compartilhamento do conhecimento adquirido com os novos funcionários que por ventura não possuíam experiência no ramo madeireiro.

Diante disso, foi possível reafirmar a tendência natural dos indivíduos em resistir a processos de mudança. Essas renovações eram enfrentadas com grande relutância por parte dos funcionários mais experientes, mantendo assim uma barreira que dificultava o aprendizado por parte de novos integrantes que eram contratados. Diante disso, foi possível constatar que funcionários que possuem maior experiência tendem a conservar os mesmos padrões e uma mesma mentalidade, sendo que poucos conseguem aceitar mudanças que levem a uma modificação nos processos.

Os dados levantados demonstraram que a organização não possuía um processo de captura do conhecimento, muitas vezes os membros mais novos não estavam motivados a trabalhar produtivamente devido à falta de material explicito que os auxiliassem na realização das atividades. O processo criativo era em grande parte barrado pela forma que o sistema era gerido, em outros casos pela resistência a inovação.

\section{Passando para um modelo de gestão do conhecimento}

Após essas observações, sugere-se a implantação de um projeto piloto demonstrando os benefícios que surgiriam, se tal processo de gestão fosse implementado, como foi o sugerido por Levett e Guenov (2000) para a indústria automobilística. Uma análise inicial foi realizada observando os seguintes tópicos na organização:

1. Motivação (quanto os empregados estão motivados para trabalhar produtivamente);

2. Captura de Conhecimento (a habilidade de se capturar conhecimento importante);

3. Armazenamento de conhecimento (a utilidade do conhecimento armazenado para a solução de novos problemas);

4. Treinamento (a efetividade dos mecanismos de treinamento de empregados);

5. Transferência de Conhecimento (a efetividade do compartilhamento de conhecimentos importantes); 
6. Pensamento Criativo (a habilidade dos empregados em criar novas soluções);

7. Identificação do conhecimento (a efetividade de identificar o conhecimento);

8. Acesso ao conhecimento (a efetividade de acesso a conhecimento importante).

Estas oito questões foram fundamentais na elaboração do escopo que foi utilizado para medir a possibilidade da implementação da gestão do conhecimento em vários aspectos dentro da organização. A utilização das mesmas foi de grande valia para a elaboração e sugestão do processo de implantação.

Seria de grande valia para este tipo de organização que as informações seguissem a espiral do conhecimento proposta por Nonaka e Takeuchi (1997) observada na figura 01.

Figura 01 - Espiral do conhecimento

Fonte: Adaptado de Nonaka e Takeuchi (1997)

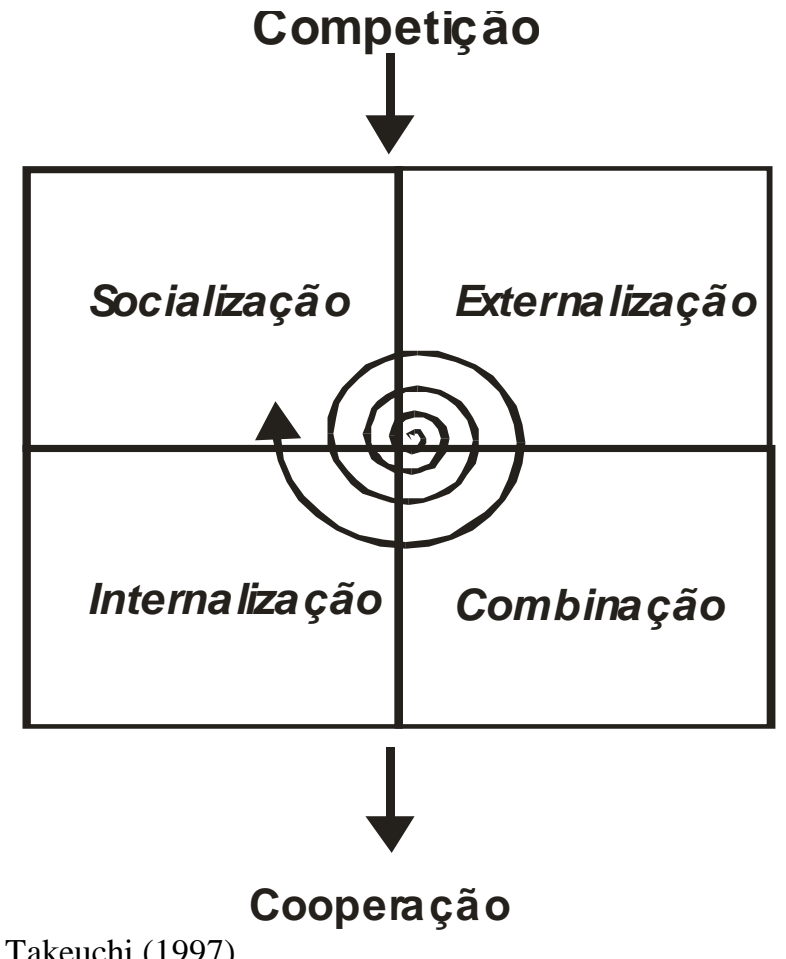

Este processo não ocorre devido ao fato deste mercado ser extremamente pequeno e controlado por empresas que não possuem o desejo da divulgação deste conhecimento, como informado pelos dirigentes da organização. Pela característica do fluxo do processo encontrado na empresa, pode-se constatar que a mesma se encontra, atualmente, em uma fase de gestão de informação.

Agregariam uma maior vantagem se passasse a exercer um Sistema de Gestão do Conhecimento, seguindo algumas das sugestões do KPMG. As sugestões da KPMG incentivam as inovações, criando novas idéias e estimulando o poder cognitivo. Essas sugestões tornam possíveis: - a captura da visão (insight) e do conhecimento dos indivíduos, torna-se disponível para 
qualquer um a qualquer hora e lugar;

- $\quad$ a simplificação da reutilização do know-how e experiência, sendo elas tácitas ou explicitas;

- incentivo a cooperação, compartilhamento, aprendizado continuo e o melhoramento nas tomadas de decisões.

As sugestões proporcionam aos compradores e vendedores da organização a possibilidade de acessar as informações de forma mais rápida e precisa, pois então possuiriam uma base de conhecimento maior.

Vasconcelos (2000) identifica três etapas fundamentais nos processos de gestão do conhecimento:

1) aquisição e criação do conhecimento: nessa fase esta incluída todo o conhecimento que a organização adquire e também o conhecimento que por ela é desenvolvido;

2) compartilhamento do conhecimento: requer um ambiente onde predomine a confiança entre os membros, sendo esta a etapa mais demorada do processo, exige que os membros se reúnam regularmente e que exista comunicação (fator crucial);

3) registro deste conhecimento: esta fase torna acessível aos que necessitam utilizar o conhecimento, proporcionando aceleração dos processos de inovação.

Foi sugerido para a organização o esquema de implantação de um Sistema de Gestão de Conhecimento abaixo:

- Justificativa:

- Concorrência;

- Vantagem competitiva.

- Objetivo:

- $\quad$ Aumentar a margem da vantagem competitiva sobre os concorrentes.

- $\quad$ Processo de Implantação:

- $\quad$ Estabelecer o responsável;

- Disseminação da cultura de Gestão do Conhecimento;

- Documentação;

- $\quad$ Seleção das ferramentas para a Gestão do Conhecimento.

- Resultados esperados:

- Compartilhamento do conhecimento;

- Maior agilidade nas tomadas de decisões;

- Vantagens Competitivas; 
- $\quad$ Lucratividade.

\section{Conclusão}

Sendo a gestão do conhecimento um movimento que agrupa e divulga conhecimento nas organizações, foi observado que a implementação seria uma tarefa de baixa complexidade para a organização, pois o número de pessoas envolvidas é pequeno e uma focalização nos objetivos seria uma tarefa fácil de atingir e de se manter.

Baseado no conhecimento dos padrões de trabalho dos concorrentes, a organização teria grande vantagem competitiva com a implantação de tal sistema de gestão. Entretanto, o fator de maior complexidade se constituiu no processo de conscientização e comprometimento dos membros da organização, para que estes participassem de forma ativa na implantação dessa metodologia de gestão.

$\mathrm{Na}$ implementação do processo seria necessário o compartilhamento e a conversão do conhecimento tácito em explícito, sendo que essa internalização levaria a organização a um nível mais elevado no mercado e, assim, a posicionaria em um patamar mais confortável perante os concorrentes. Com tal elevação a organização poderia expandir seus mercados e assim se fortalecer.

Os produtos comercializados são totalmente intangíveis, pois trabalham somente com a informação. Os dados fornecidos por indicadores de mercado do ramo madeireiro são transformados em informações que passam a ser comercializadas para os clientes norte americanos. Tanto os fabricantes de produtos brutos e semi-beneficiados de pinus, quanto os beneficiadores, que necessitam vender e comprar a matéria-prima podem usufruir dessas informações e assim contar sempre com um mercado de comercialização ágil.

Tendo como base estas afirmações, as organizações buscam implementar novos modelos de gestão de forma a inserir a gestão do conhecimento em suas atividades e assim, promover um melhor desempenho no mercado.

Todavia, mesmo diante das vantagens apresentadas, a organização se manteve fechada quanto ao fato de adotar a metodologia de Gestão do Conhecimento. Alegou para tanto, que esse processo geraria conflitos internos, e poderia haver a possibilidade de vazamento de informações para os concorrentes. Também alegou que este processo poderia causar prejuízos nas transações rotineiras pelo fato de requere uma mudança cultural por parte dos integrantes.

\section{ABSTRACT}


This article seeks to demonstrate the need of implementing Knowledge Management in small North American companies that markets plantation pine lumber. The need for this was observed due to the difficulty found, by the new employees, in the learning and accomplishment of activities, because the organization didn't possess support material that demonstrated the processes flow. The objectives of this work were to determine factors that hindered the implementation and to diagnose the barriers that existed for this, and to elaborate methods to overcome the barriers. The methodology used was a case study; this was used to assign the several stages of the processes that involve the commercialization of Brazilian plantation pine in the North American market and to propose necessary methods for the use of the Knowledge Management in the organization.

Keywords: Knowledge Management - International Commercialization, Lumber Industries.

\section{Referências}

CHOO, C. W. Information management for the intelligent organization: the art of scanning the environment. Information Today Inc. $3^{\text {rd }}$ ed. New Jersey: Medford, 2002.

DAVENPORT, T.; PRUSAK, L. Conhecimento empresarial: como as organizações gerenciam o seu capital intelectual. Rio de Janeiro: Campus, 1998.

KPMG INTERNATIONAL. Disponível em: 〈http://www.kpmg.com>. Acesso em: 3 abr. 2004.

LEONARD, D. Nascentes do saber - criando e sustentando as fontes de inovação. Rio de Janeiro: Fundação Getúlio Vargas, 1998.

LEVETT, G. P.; GUENOV, M. D. A methodology for knowlege managment implementation. Journal of Knowledge Management, v. 4, n. 3, p. 258-269, 2000.

NONAKA, I.; TAKEUCHI, H. Criação de conhecimento na empresa. Rio de Janeiro: Campus, 1997.

ROBERTSON, S. A tale of two knowledge-sharing systems. Jornal of Knowledge Managment, v. 6, n. 3, p. 295-308, 2002.

THUROW, L. C. O futuro do capitalismo: como as forças econômicas de hoje moldam o mundo de amanhã. Rio de Janeiro: Rocco, (1997).

VASCONCELOS, M. C. R. L. Cooperação universidade-empresa na pós-graduação: contribuição para a aprendizagem, a gestão do conhecimento e a inovação na indústria mineira. Belo Horizonte: Escola de Ciência da Informação da UFMG, 2000. 